See discussions, stats, and author profiles for this publication at: https://www.researchgate.net/publication/26371849

\title{
A "Primer" in Conceptual Metaphor for Counselors
}

Article in Journal of counseling and development: JCD · October 1999

DOI: 10.1002/.1556-6676.1999.tb02464.x

CITATIONS

47

4 authors, including:

Scott A. Wickman

Northern Illinois University

5 PUBLICATIONS 94 CITATIONS

SEE PROFILE

Steven Fesmire

Radford University

32 PUBLICATIONS 315 CITATIONS

SEE PROFILE

Some of the authors of this publication are also working on these related projects:

John Dewey and Moral Imagination View project

Oxford Handbook of Dewey View project
READS

117

M. Harry Daniels

University of Florida

33 PUBLICATIONS 457 CITATIONS

SEE PROFILE 


\title{
A "Primer" in Conceptual M etaphor for Counselors
}

\author{
Scott Allen Wickman, M. H arry D aniels, Lyle J. W hite, and Steven A. Fesmire
}

Conceptual metaphor provides a potentially powerful counseling framework, generalizable across theoretical orientations. According to the conceptual perspective, metaphor is not merely a matter of language, but is an indispensable dimension of human understanding and experience whereby more abstract ideas (like relationships) are understood in terms of more concrete experiences (like journeys). Consequently, when a couple in counseling says, "we're just spinning our wheels," they are not only using a common colloquial expression, but also giving information about how they conceptualize their relationship. This article provides a theoretical foundation for use of conceptual metaphor and offers examples of its potential for counseling.

\section{M}

etaphoric language has been an important therapeutic tool since the first counselor attempted to understand fully a client's experience of the world. Traditionally, counselors have developed metaphors to demonstrate empathy and to suggest alternative interpretations of presenting problems. This use of metaphor, created by the counselor, does not change a client's problems; rather, it changes perception of the problem and allows for solutions as yet unconsidered. In this manner, metaphor has provided both a linguistic tool to facilitate empathy and an intervention technique with a history of therapeutic value (Bryant, Katz, Becvar, \& Becvar, 1988; Cirillo \& C rider, 1995; H aley, 1973; Hoskins \& Leseho, 1996; S. B. Kopp, 1971; Leary, 1990; M acC ormack, 1997; M CM ullen, 1996; M yers, 1998; Watzlawick, 1978; Watzlawick, Weakland, \& Fisch, 1974).

Studies in cognitive linguistics have advanced a contemporary theory of metaphor that suggests metaphors represent more than rhetorical or linguistic techniques. These studies propose that humans use metaphor not only for communication purposes but al so to experience and understand their lives (Johnson, 1987, 1993; L akoff, 1987, 1993, 1996; Lakoff \& Johnson, 1980, 1999; M cN eill, 1992; Q uinn, 1987; Simpson, 1996; Turner, 1987). To understand abstract ideas or events, even as such events are occurring, individuals access their knowledge of concrete experiences and apply them metaphorically. This continuous conceptual referencing of abstract ideas or events to concrete, bodily based experiences is termed conceptual metaphor (Lakoff \& Johnson, 1980).
The purpose of this article is to discuss the use of conceptual metaphor and its special relevance to counseling. We contend that this contemporary theory of metaphor (i.e., cognitive linguistics) allows counselors a more complete and rapid access to a client's conceptual world than is provided by a more traditional understanding of metaphor (e.g., Cirillo \& Crider, 1995; S. B. Kopp, 1971; Ricoeur, 1991). Because most conceptual metaphors are so common, pervasive, and mundane, they generally go unnoticed by both counselor and client. We contend that a more thorough understanding of conceptual metaphor provides counselors a framework for recognizing the underlying significance of metaphors and enables counselors to make better use of their occurrence.

\section{METAPHOR IN COUNSELING}

Certainly therapists know about and use metaphor in their work. Bryant et al. (1988) surveyed members of the A merican A ssociation of M arriage and Family Therapists (A A M FT) and found that $95 \%$ (of those who responded) used metaphor, defined as "any verbal or concrete illustration, description, or reference designed to bring about perceptual and/or behavioral change" (p. 113). Recently, M yers (1998) discussed how bibliotherapy can be used as an effective strategy for cocreating therapeutic metaphors in counseling. Perhaps the best known use of therapeutic metaphor is the type popularized by Milton Erickson, who would create analogous stories and jokes that were structurally similar to clients' situations but that made no direct mention of the clients nor their descriptions of their problems

Scott A llen Wickman is a doctoral candidate at Southern Illinois University at Carbondale and a guidance counselor at Ramsey H igh School, Ramsey, Illinois. M. H arry Daniels is the chair of the Counselor Education D epartment at the University of Florida, Gainesville. Lyle J. White is an associate professor at Southern Illinois University at Carbondale. Steven A. Fesmire is an assistant professor in the D epartment of Philosophy at East Tennessee State University, Johnson City. This project was supported in part by the O ffice of Research and D evelopment A dministration, Southern IIlinois U niversity at Carbondale (SIUC). The authors thank Keith Joritz, Jayne Tristen, M ark Johnson, Todd H edinger, and Cynthia Campbell for their helpful suggestions. Correspondence regarding this article should be sent to LyleJ. White, D epartment of Educational Psychology and Special Education, Southern IIlinois U niversity at Carbondale, Carbondale, IL 62901-4618 (e-mail: Iwhite@siu.edu). 
(Bandler \& G rinder, 1975; Bowman, 1992; Erickson \& Rossi, 1979; H aley, 1973). Suffice it to say, metaphor is used frequently in counseling and typically is initiated by the counselor to effect client change.

We believe that viewing metaphor simply as an intervention technique is a narrow and incomplete perspective. Contemporary metaphor theory offers counsel ors a framework for becoming more attuned to the language and conceptual understandings of their clients. In addition, contemporary metaphor theory provides a structure for developing interventions that fit more naturally with client thinking and perception. In Piagetian theory, such a fit makes interventions more easily assimilated (Piaget, 1947/1973). In Batesonian theory, the interventions are "appropriately unusual" (A ndersen, 1995, p. 15)-different, but not too different from client thinking (A ndersen, 1992).

\section{CONCEPTUAL METAPHOR: THE EMERGING VIEW}

A sjust noted, the use of metaphor in counseling is far from a recent development. W hat is new, however, is the realization that metaphors are not merely linguistic expressions, but are integral to the very way we think (Johnson, 1981, 1987, 1993). A s Lakoff (1993) stated, "the locus of metaphor is not in language at all, but in the way we conceptualize one mental domain in terms of another" (p. 203). According to this perspective, metaphor is an indispensable dimension of human understanding and experience and is essential to the way individuals think, reason, perceive, imagine, communicate, believe, and so forth (Johnson, 1987). There is evidence that even the most basic abstract concepts are understood through multiple and sometimes inconsistent conceptual metaphors (G ibbs, 1994; Lakoff, 1993; Q uinn, 1987; Turner, 1987).

This means that metaphor is essential to "our having of a world" (Johnson, 1987, p. 205) and that all fundamental concepts are metaphoric. For example, conceptualizing "time as a val uable commodity," allows one to "spend" time, "save" time, "waste" time, and so forth. For this reason, people organize their lives around their own sets of personal and cultural metaphors: Who they are, how they understand situations, the way they relate to others, and what they see as possible courses of action all depend on which metaphors happen to constitute the fabric of their experience (J ohnson, 1987). A Ithough these mental processes are not directly observable, evidence for their metaphoric nature can be found in the verbal and nonverbal components of everyday communication (M cN eill, 1992). A bundant examples of congruence between individuals' verbal and nonverbal metaphoric expressions can be found in the video documentary Couples A rguing ( $G$ antz \& G antz, 1985), for example a wife shouting at her husband about his treatment of her children, "you come in here and you just wipe them out" as she concurrently makes a dramatic sweeping gesture with her hand. Similarly, the same conversation includes her bringing her hands together, raising her arms, and quickly pulling her hands apart as she says, "you just explode around them," using a conceptual mapping from the ANGER IS PRESSURE IN A CONTAINER set of metaphors to understand and describe her husband's behavior toward her children.

Traditional approaches to using metaphor in counseling seem to depend on a counselor's intuitive abilities. There are, however, at least two inherent flaws in this approach. First, an intuitive intervention, although it seems appropriate at the time, may depend heavily on guesswork. Thus, metaphors chosen by a counselor may or may not fit within a client's conceptual framework; after all, it is a guess. Second, intuitive ability probably exists on a continuum. For a master counselor (e.g., A lbert Ellis, Virginia Satir, M ilton Erickson, $\mathrm{C}$ arl Rogers), this dependence on intuition may not be limiting (W ickman, 1999). For others, a more systematic understanding of a client's metaphoric language and conceptual structuring should improve the goodness of fit of their therapeutic interventions.

We suggest that familiarity with the most common and pervasive metaphors and how they are referenced from one domain to another will provide counselors access to a qualitatively different understanding of a client's world. A Ithough counselors cannot know precisely what a client is thinking or experiencing, they can know their client's thoughts and experiences are structured this way rather than that, with these possibilities rather than those. Thought processes that otherwise would have escaped notice now can be identified and brought into the therapeutic conversation. In addition, the ability to perceive clients' conceptual metaphors enhances counselors' abilities to access and reflect the frameworks through which clients understand and experience their worlds. As Lakoff and Johnson (1980) noted, "In therapy, much of self-understanding involves consciously recognizing previously unconscious metaphors and how we live by them" (p. 233). By understanding metaphor as a structure of a person's conceptual world, counselors are better able to facilitate recognition of personal metaphors and enhance self-understanding. Furthermore, counselors are better able to work within clients' existing metaphoric structure rather than impose metaphors (which may or may not fit) originating from the counselor's schema.

A dopting language that is more consistent with the client's way of thinking increases a practitioner's effectiveness (Bandler \& G rinder, 1975; Latz, 1996; Rogers, 1957; Watzlawick, 1978; Watzlawick et al., 1974; Wickman, 1999). Familiarity with conceptual metaphor provides a method for developing and using such language; moreover, the counselor is able to hear previously unrecognized richness in client language and respond in kind. In this way, the effective use of metaphor is not left to the intuitive sensing of counseling "gurus" but can become an intelligently controlled and deliberate approach to therapeutic inquiry.

\section{Conceptual M etaphor as Cross-D omain M appings}

The first step in using conceptual metaphor as an intentional counseling tool is to understand the nature of cross- 
domain mappings. Traditionally, counselors have perceived metaphor as "a way of speaking in which one thing is expressed in terms of another, whereby this bringing together throws new light on the character of what is being described" (S. B. Kopp, 1971, p. 17). Other theorists (Johnson, 1987, 1993; Lakoff, 1987, 1993; Lakoff \& Johnson, 1980, 1999; McNeill, 1992: Quinn, 1987; Turner, 1987) have operationalized metaphor specifically as cross-domain mappings in which the properties of one concept, from a concrete source domain, are transferred onto and structure the perception of an abstract concept, in a target domain. To illustrate, a couple seen in counseling by one of the authors reported, "we're stuck, we're just spinning our wheels; this relationship isn't going anywhere" (metaphoric language emphasized). As evidenced by their language, this couple described and perceived their relationship metaphorically. They were using their knowledge and experience of journeys (source domain) to understand and portray their relationship (target domain). One part, or possible entailment, of a journey is to travel in a vehicle. On a journey, a vehicle, like a relationship, can get stuck. Once it stops moving, its passengers (the relationship partners) become bewildered, frustrated, and uncertain of how to get it back in motion.

The language used in the preceding illustration suggests that the couple attributed to their relationship the same properties they attributed to a stuck vehicle. Another way to say this is that they were perceiving their relationship according to what they knew about stuck vehicles. Naturally, they wanted to act in a way that would move the relationship forward (i.e., to make progress). In this example, the couple saw their options for action delineated by the RELATIONSHIP IS A JOURNEY metaphor system. Their knowledge and bodily based experience from the concrete source domain (journey) carried over to organize their thinking and perception of the more abstract target domain (relationship).

The metaphoric understanding of a relationship, or any long-term endeavor, as a journey is hardly unique to the couple just mentioned. In fact, the journey metaphor is one of the more pervasive metaphors across domains, languages, and cultures. As Gibbs (as cited in Azar, 1995) explained

Through bodily experiences, such as standing, walking, eating, and other interactions with the physical environment, people develop mental models-image schemas of concepts such as balance, containment, resistance, and verticality. ... These same concepts crop up in language. For example, another image schema is "source-path-goal." Humans often move along a path to reach a goal-across the room to get a book, down the road to see a friend. People recognize abstract concepts, "life is a journey" and sayings such as "we're at the crossroads," and "we've gotten off the track" because they have an innate understanding of the source-path-goal theme. (p. 20)

\section{The Aspects of Conceptual Metaphor}

Contemporary metaphor theorists suggest three aspects to conceptual metaphor: mnemonic, cross-domain mapping, and everyday language (see Figure 1). Cross-domain map-

\section{Mnemonic (name of the set of mappings)}

LOVE RELATIONSHIP IS A JOURNEY

2. Cross-domain mappings

Source Domain

Target Domain

a. travelers in a vehicle $\longrightarrow$ partners in the relationship

b. obstacles to motion $\longrightarrow$ problems in the relationship

\section{Everyday language}

a. "We're stuck and feel like this relationship isn't going anywhere."

"We're just spinning our wheels." "We're at a standstill in this

relationship." "We've come a long way through the years."

"She's carrying around a lot of baggage from past relationships."

b. "His mother kept getting in the way, so we told her to back off."

"We got off to a rocky start." "We ran into a lot of roadblocks when

we started going together, but now we're cruising along."

"I didn't see it coming." "I don't want to go through that again."

\section{FIGURE 1}

\section{Three-Part Analysis of a Conceptual Metaphor: An Illustration}

ping, already discussed, is explored further in light of representing one of the three aspects.

The mnemonic. The mnemonic is the name of a set of related metaphors. For example, the mnemonic RELATIONSHIP IS A JOURNEY includes the metaphors (i.e., cross-domain mappings) that relationship partners are travelers, the relationship is a vehicle, relationship problems are obstacles to motion, and so forth (see Figure 1). Other mnemonics are also likely to be present in discussions about relationships. In fact, Quinn (1987) found the following relationship mnemonics to prevail in Western culture: RELATIONSHIP IS A JOURNEY, RELATIONSHIP IS A BUSINESS PARTNERSHIP, RELATIONSHIP IS A MANUFACTURED PRODUCT, RELATIONSHIP IS A SAFE HAVEN, RELATIONSHIP IS AN ORGANISM, AND RELATIONSHIP IS A DURABLE BOND. On the basis of her research, Quinn concluded that many difficulties in marriage occur when one spouse has a particular metaphor (e.g., RELATIONSHIP IS A BUSINESS PARTNERSHIP) that conflicts with the expectations generated by the other spouse's dominant metaphor system (e.g., RELATIONSHIP IS AN ORGANISM).

To illustrate, the person who perceives relationships as business partnerships may experience relationships as investing in contracts that stipulate rewards. Such rewards (e.g., respect) are contingent on contributions to the relationship (e.g., income earned) and are in contrast to the perception ofrelationships as organisms. For a person whose perception is structured by RELATIONSHIP IS AN ORGANISM, a relationship is nurtured and the partners grow together 
without deference to just rewards for individual contributions. It takes little imagination to see how partners using different sets of metaphors could experience difficulty resolving conflict. It is almost as if they are speaking different languages or living in different conceptual universes. A nd in many ways they are.

Cross-domain mappings. Each mnemonic in fact represents a whole set of correspondences that are mapped from one domain onto another. Specifically, one domain provides a source or referent for understanding the other domain, called the "target." A gain, the source domain, through which the target domain is experienced and understood, contains knowledge that people al ready have, based on their own bodily experiences and what they have learned from other people. $\mathrm{H}$ ence, knowledge from the bodily based source is "mapped" across domains onto the target in order to structure and organize how the target domain is perceived and understood. For example, as previously stated, RELATIONSHIP IS A JOURNEY includes cross-domain mappings such as the partners are travelers, the relationship is their vehicle, the course of the relationship is a path, problems in the relationship are obstacles to motion, and so forth. On the other hand, RELATIONSHIP IS A BUSINESS PARTNERSHIP includes cross-domain mappings like relationship partners are contractors, the relationship is a contractual agreement, the course of the relationship is a ledger, problems in the relationship are debits, and so forth. Yet a third perspective on relationships is found in RELATIONSHIP IS AN ORGANISM. In this case, relationship partners are caretakers of the organism, the relationship is a living organism, duration of the relationship is the life cycle of the organism, problems in the relationship inhibit growth, and so forth.

To reiterate, people's perception of an event or concept consists of knowledge and experience from a source domain being "mapped" or transferred onto a target domain. What a couple knows about journeys, business, organisms, and so forth structures their understanding and experience of relationships. For example, relationships, like vehicles, get stuck, break down, and run out of gas. As perceived through the RELATIONSHIP IS A JOURNEY metaphor, progresS in a relationship can be impeded when something - or someone-gets in the way. If an obstacle is insurmountable, the journey or relationship stops. To summarize, "mapping knowledge about journeys onto knowledge about love permits us to reason about love using the knowledge we use to reason about journeys" (Lakoff, 1993, p. 207).

Everyday language. People's everyday language contains metaphoric expressions so pervasive, common, and seemingly mundane that they go largely unnoticed. Lakoff (1993) described this as the "surface realization" (p. 203) of conceptual metaphor: Everyday language is representative of the underlying, deeper cross-domain mappings that take place at the conceptual level. For example, couples describe their relationships as "at a dead end" or "making a lot of progress" because they are conceptualizing their relationship according to their knowledge and experience of journeys. If they were conceptual izing their relationship in terms of a business partnership, they might say, "I've invested a lot in this relationship," "I've given you the best years of my life," or "I don't get any credit for all the stuff I do." Similarly, people with a prevalent metaphor of RELATIONSHIP IS AN ORGANISM may be heard to say "we've grown a lot together," "this relationship is on its deathbed," "we're starting to branch out and do things with other people."A sthese examples demonstrate, everyday language reflects the crossdomain mappings that structure how people make meaning of the world. Taken together, mnemonics, cross-domain mappings, and everyday language offer a means of showing concretely how people reason about and experience the worlds in which they live.

\section{Case Examples}

O nce a counselor becomes aware of the pervasiveness of conceptual metaphor, therapeutic interventionscan be more appropriately structured around metaphors expressed and experienced by the client. Three of the following case examples are taken from our counseling experiences and illustrate the clinical utility of this knowledge. The final example is taken from the counseling session between $C$ arl Rogers and G loria (Rogers \& Wood, 1974; Shostrom, 1965; W ickman, 1999) and illustrates the intuitive use of conceptual metaphor by a master clinician.

Case 1. A recently retired couple entered counseling saying "we're not getting along" and "we don't know where to go from here." A fter hearing more RELATIONSHIP IS A JOURNEY expressions (e.g., "I go out of my way for you," "we've been through this before," "I wish we could get over this hump"), the counselor began to respond and ask questions using parallel language. "It's been quite a journey for the two of you," he said. The couple enthusiastically agreed. Then he asked, "Imagine you were taking a journey in a car: Who would be the driver?" The wife pointed to her husband, who pointed to himself. The counselor looked at the wife and asked, "H ow safe do you feel as a passenger, with him as the driver?" She replied that she did not feel safe and that they were "headed straight for a wreck."The counselor continued by asking, "If this really were a vehicle, what would you do?" "I'd jump out!" she said. H earing this comment, the husband's mouth visibly dropped and he gave other indications that he had heard his wife's concerns about their marriage in a way he never had before.

Case 2. A nother way metaphor can be approached in counseling is to help counselors and clients use language that leads to clearer and more effective communication. To illustrate, a divorced mother in counseling was troubled by her apparently futile efforts to interact better with her 14-year-old son. When asked to pay attention to her son's language during their conversations, the mother reported that her son used expressions such as "don't you hate pay backs?" "you owe me one," "you're selling me short," and "I don't buy that." These expressions showed that the son consistently employed terminology from the RELATIONSHIP IS A BUSINESS PARTNERSHIP conceptual metaphor, one of many 
metaphors found within the MORAL ACCOUNTING metaphor (Johnson, 1993).

As a part of the counseling process, the counselor discussed some details of this metaphor with the mother, including how the concept of a business transaction seemed to influence her son's perception of their relationship. In addition, she and the counselor practiced using business metaphors in session. Through this experience, the mother was sensitized to her son's conceptual viewpoint; that is, she began to use his conceptual metaphor for the relationship in her conversations with him. Subsequently, the mother reported that when she used business terminology, her son was more verbally responsive and their communication improved.

Case 3. Rogers (1957) noted that clients will sometimes disagree with statements reflected to them by the counselor, even when the statement is repeated verbatim. In this way, contemporary metaphor theory offers counselors another means by which to reflect client perceptions of presenting problems. By observing and using language consistent with the everyday metaphors clients use, counselors can more precisely reflect feelings and clarify underlying meanings. For example, a counselor noticed a husband using business transaction metaphors to discuss his marital relationship (e.g., "I've put a lot into this family that I don't get credit for." "I've held my end of the bargain." "I feel like I am indebted to her for the past and nothing I do is good enough."). The counselor then asked, "W hat investments are you willing to make in your wife?" The husband responded, "You know, I can't look at my wife as an 'investment;' she's a lot more than that to me." In this case, the husband consistently had used business language to describe his relationship. N onetheless, the inadequacy of this metaphor became apparent to him once it was made overt, and he was able to explore alternative ways of looking at the relationship.

Case 4. Rogers (1957) posited that empathy was one of the core conditions for a helping relationship and that the most important aspect of empathy was that it be perceived by the client. U sing metaphoric language from the client's conceptual domain can enhancethe client's perception of being heard and can expedite rapport building. The G loria session (Rogers $\&$ Wood, 1974; Shostrom, 1965; Wickman, 1999) provides some clear illustrations of Rogers's apparent intuitive appreciation of the conceptual nature of metaphor.

G loria: I want to approve of me, always. But my actions won't let me. I want to approve of me.

Rogers: You sound as though your actions are kind of outside of you. You want to approve of you but what you do somehow won't let you approve of yourself.

G loria: Right! (Wickman, 1999, pp. 262-263)

Throughout the session Rogers seems to intuitively understand that Gloria is perceiving THE PSYCHOLOGICAL SELF IS A CONTAINER. The container holds psychological states and personality traits. In her idealized perception of herself, G loria is not able to accept her container holding conflict- ing states and traits. Rogers recognizes this and uses the phrase "your actions are kind of outside of you" to convey his understanding of her metaphoric container of "self." At this point of the interview, her metaphoric container for her self as a "good and sweet" mother does not allow for actions that she deems "ornery." H er enthusiastic acceptance of Rogers's language suggests that this exchange has helped build rapport between them (W ickman, 1999).

\section{CONCLUSION}

Speaking a client's language has long been understood as a means to join with clients, gain their trust, and bring about the necessary and sufficient conditions for change (Rogers, 1957). C ounsel ors who are familiar with conceptual metaphor advance their capacity for communicating with language from the same metaphor systems as their clients and for expressing a deeper awareness of clients' problems By using language that is congruent with their clients' conceptual metaphors, we contend that counselors can communicate more empathically and respectfully while helping clients explore the logical conclusions of an issue more efficiently and elegantly. Knowing how entities and knowledge are referenced (mapped) from one domain onto another enables a counselor to use language congruent with a client's perceptual world. Consequently, the cross-domain mappings frame the therapeutic conversation, while allowing for any of the various theoretical counseling orientations to be practiced.

Conceptual metaphor offersa communicative tool to help counsel ors respect, understand, and reflect clients' conceptual systems. Furthermore, by attending to the metaphoric structure of clients' language, counselors are able to use that same metaphoric structure to frame their therapeutic language. A long these lines, Lakoff and J ohnson (1980) have argued that " $M$ etaphorical imagination is a crucial skill in creating rapport and in communicating the nature of unshared experience" (p. 231). Lakoff and Johnson, like Frankl (1963), also contended that much of clients' selfunderstanding is the product of the search for appropriate personal metaphors that give meaning to their lives. Consequently, counselors who recognize their clients' conceptual metaphors are better able to respond effectively to client concerns. Understanding conceptual metaphor allows counselors to join with clients through increased rapport and empathy and structure therapeutic interventions that are more consistent with clients' existing frameworks.

Counseling is a rich database for conducting research into conceptual metaphor. Although previous authors (e.g., R. R. Kopp, 1995; Kozak, 1992; Rosenblatt, 1994) have related conceptual metaphor theory to counseling, and others have studied the effectiveness of therapeutic metaphor as a counseling intervention (for an overview of this research, see Ingram, 1994, and M cM ullen, 1996), we are currently applying conceptual metaphor as a framework for investigating the language used in therapeutic conversations. O ur initial findings suggest that clients use meta- 
phors pervasively. Some metaphors occur intermittently, whereas others dominate perceptions about a problem. We are al so finding that the interpretation of metaphors is context dependent. Each conversation participant brings with her or him a set of existing metaphors and experiences that structures their particular language and understanding (S. G. Kopp, 1998). Because these differences of meaning exist, counsel ors can increase common understanding with clients by consciously making metaphor mappings a part of the therapeutic conversation. In future investigations, we intend to address research questions such as how clients' metaphors change over time, how counselors' metaphors compare and interact with those of their clients, and how the use of differing metaphoric language by family members relates to their reasons for seeking counseling. The effects of training counselors to use conceptual metaphor in their sessions will also be examined.

O ur enthusiasm for the potential of conceptual metaphor to nourish clinical research and training in the counseling profession is unabashed; however, the breadth of this line of research is greater than can be attended to by one research team. Therefore we hope this article will serve to inform and stimulate the interest of others who find these notions intriguing.

\section{REFERENCES}

Andersen, T. (1992). Reflections on reflecting with families In S. M. M cN amee $\&$ K. J. Gergen (Eds.), Therapy as social construction (pp. 54-68). London: Sage.

A ndersen, T. (1995). Reflecting processes; acts of informing and forming: You can borrow my eyes, but you must not take them away from me! In S. Friedman (Ed.), The reflecting team in action: Collaborative practice in family therapy (pp. 11-37). N ew York: Guilford Press.

Azar, B. (1995). Breaking through barriers to creativity. APA Monitor, 26(8), pp. 1, 20.

Bandler, R., \& G rinder, J. (1975). Patterns of the hypnotic: Techniques of Milton H. Erickson, M.D. Cupertino, CA: M eta-Publications.

Bowman, G. (1992). Using therapeutic metaphor in adjustment counseling. Journal of Visual Impairment and Blindness, 86, 440-442.

Bryant, L., Katz, B., Becvar, R., \& Becvar, D. (1988). The use of therapeutic metaphor among members of the AA M FT. The A merican Journal of Family Therapy, 16, 112-120.

Cirillo, L., \& Crider, C. (1995). Distinctive therapeutic use of metaphor. Psychotherapy, 32, 511-519.

Erickson, M. H., \& Rossi, E. L. (1979). Hypnotherapy: A n exploratory casebook. N ew York: Irvington Publishers.

Frankl, V. E. (1963). Man's search for meaning (Rev. ed.). N ew York: Washington Square Press.

G antz, J., \& G antz, H. (Directors and producers). (1985). Couples arguing [V ideotape]. (Available from Filmmakers Library, 124 E. 40th St., N ew York, 10016)

G ibbs, R. (1994). The poetics of mind. N ew York: Cambridge U niversity Press.

H aley, J. (1973). Uncommon therapy: The psychiatric techniques of M ilton H. Erickson, M.D. N ew York: N orton.

H oskins, M., \& Leseho, J. (1996). Changing metaphors of the self: Implications for counseling. Journal of Counseling \& Development, 74, 243-252.

Ingram,J.L. (1994).The role of figurative language in psychotherapy:A methodological examination. M etaphor and Symbolic A ctivity, 9, 271-288.

Johnson, M. (1981). Knowing through the body. Philosophical Psychology, 4, 3-18.
Johnson, M . (1987). The body in the mind: The bodily basis of meaning, imagination, and reason. Chicago: University of Chicago Press.

Johnson, M . (1993). M oral imagination: Implications of the cognitive sciences for moral theory. Chicago: U niversity of C hicago Press.

Kopp, R. R. (1995) M etaphor therapy: Using client generated metaphors in psychotherapy. N ew York: Brunner/M azel.

Kopp, S. B. (1971). G uru: M etaphors from psychotherapists. Palo A Ito, CA: Science and Behavior.

Kopp, S. G. (1998). Q uantifying conceptual metaphor: A n inter-rater reliability study. Unpublished master's thesis, Southern Illinois University at Carbondale.

Kozak, A. (1992). The epistemic consequences of pervasive and embodied metaphor: A pplications to psychotherapy. Theoretical and Philosophical Psychology, 12, 137-154.

Lakoff, G. (1987). Women, fire, and dangerous things: What categories reveal about the mind. Chicago: University of Chicago Press.

Lakoff, G. (1993). The contemporary theory of metaphor. In A . O rtony (Ed.), M etaphor and thought (2nd ed., pp. 202-251). N ew York: Cambridge University Press.

Lakoff, G. (1996). M oral politics: What conservatives know that liberals don't. Chicago: University of Chicago Press.

Lakoff, G., \& Johnson, M . (1980). M etaphors we live by. Chicago: University of Chicago Press.

Lakoff, G., \& Johnson, M . (1999). Philosophy in the flesh:The embodied mind and its challenge to Western thought. N ew York: Basic Books.

Latz, M. (1996). Brief report: O $n$ an exercise for training beginning marital and family therapists in language skills. Journal of $M$ arital and Family Therapy, 22, 121-126.

Leary, D. E. (1990). Psyche's muse: The role of metaphor in the history of psychology. In D. E. Leary (Ed.), M etaphors in the history of psychology (pp. 1-78). N ew York: Cambridge University Press.

M acC ormack, T. (1997). Believing in make-believe: Looking at theater as a metaphor for psychotherapy. Family Process, 36, 151-169.

McMullen, L. M. (1996). Studying the use of figurative language in psychotherapy: The search for researchable questions. M etaphor and Symbolic A ctivity, 11, 241-255.

M cN eill, D. (1992). H and and mind: What gestures reveal about thought. Chicago: University of Chicago Press.

$M$ yers, J. E. (1998). Bibliotherapv and DCT: Co-constructina the therapeutic metaphor. Journal of Counseling \& D evelopment, 76, 243-251.

Piaget, J. (1973). The psychology of intelilgence. (M. Piercy and D. Elkind, Trans.). Savage, M D : Littlefield, A dams, and Co. (O riginal work published in 1947)

Q uinn, N. (1987). Convergent evidence for a cultural model of A merican marriage. In D. H olland \& N. Q uinn (Eds.), Cultural models in language and thought (pp. 173-192). N ew York: Cambridge University Press.

Ricoeur, P. (1991). Word, polysemy, metaphor: C reativity in language. In M.J.Valdes (Ed.), A Ricoeur reader: Reflection and imagination ( $\mathrm{pp}$. 65-85). Toronto: University of Toronto Press.

Rogers, C. (1957). The necessary and sufficient conditions of therapeutic personality change. Journal of Consulting Psychology, 21, 95-103.

Rogers, C. R., \& Wood, J. K. (1974). Client-centered theory: Carl A. Rogers. In A. Burton (Ed.), O perational theories of personality ( $\mathrm{pp}$. 211-258). N ew York: Bruner/M azel.

Rosenblatt, P. (1994). M etaphors of family systems theory: Toward new constructions. N ew York: G uilford Press.

Shostrom, E. L. (Producer). (1965). Three approaches to psychotherapy [Film]. O range, CA: Psychological Films.

Simpson, P. (1996). The dynamic co-construction of discourse: Listening and speaking in "good-enough" understanding [O n-line]. Available: HTTP://W W W.SFU.CA/ PSIM PSO N/CO LLO Q W W W.HTM

Turner, M . (1987). D eath is the mother of beauty: $M$ ind, metaphor, criticism. Chicago: U niversity of Chicago Press.

Watzlawick, P. (1978). The language of change. N ew York: Basic Books.

Watzlawick, P., Weakland, J. H., \& Fisch, R. (1974). Change: Principles of problem formation and problem resolution. $\mathrm{N}$ ew York: $\mathrm{N}$ orton.

Wickman, S. A. (1999). "M aking something of it": A $n$ analysis of the conversation and language of Carl Rogers and Gloria. Unpublished doctoral dissertation, Southern Illinois University at Carbondale. 